\title{
Brasicáceas y perspectivas de control biológico del insecto plaga Plutella xylostella (Lepidóptera: Plutellidae) utilizando Bacillus thuringiensis
}

\author{
Brasicaceas and perspectives of biological control of the insect Plutella \\ xylostella (Lepidoptera: Plutellidae) using Bacillus thuringiensis
}

Julieth Mena Guerrero

Investigadora del Grupo de Investigación Genética, Biología Molecular y Bioinformática (Genbimol) del Departamento de Ciencias Biológicas y Ambientales de la Facultad de Ciencias Naturales e Ingeniería de la Universidad de Bogotá Jorge Tadeo Lozano, Bogotá, D. C., Colombia

\begin{abstract}
Javier Hernández Fernández
Profesor asociado y líder del Grupo de Investigación Genética, Biología Molecular y Bioinformática (Genbimol) del Departamento de Ciencias Biológicas y Ambientales de la Facultad de Ciencias Naturales e Ingeniería de la Universidad de Bogotá Jorge Tadeo Lozano, Bogotá, D. C., Colombia

http://orcid.org/0000-0001-8442-9266

javier.hernandez@utadeo.edu.co
\end{abstract}

Fecha de recepción: 20 de junio de 2017

Fecha de aceptación: 30 de septiembre de 2017

Sugerencia de citación: Mena Guerrero, J. y Hernández Fernández, J. (2017). Brasicáceas y perspectivas de control biológico del insecto plaga Plutella xylostella (Lepidóptera: Plutellidae) utilizando Bacillus thuringiensis. Mutis, 7(2), 7-22, en prensa, doi: http://dx.doi.org/10.21789/22561498.1245

Editor: Hernández Fernández, J. javier.hernandez@utadeo.edu.co

\section{RESUMEN}

La Plutella xylostella (L.) es un insecto plaga que afecta principalmente los cultivos de brasicáceas o crucíferas como el repollo, coliflor, brócoli y rábano, entre otros. Las limitaciones del rendimiento y calidad de estos cultivos se deben principalmente al difícil manejo de esta plaga. En la actualidad, para controlar la $P$. xylostella se utilizan insecticidas de síntesis química, como piretroides, carbamatos u organofosforados, los cuales tienen acción inmediata pero causan efectos adversos en la salud y en el ambiente. Adicionalmente, la ausencia de enemigos naturales capaces de controlar a sus poblaciones, y su resistencia a numerosos insecticidas convencionales hacen que este insecto se establezca rápidamente en áreas productoras de brasicáceas. Se calcula que los costos mundiales asociados al control de la $P$. xylostella, sumados a las pérdidas en la producción agrícola, están entre cuatro y cinco billones de dólares anuales.

Se han propuesto alternativas seguras, efectivas y de menor impacto ambiental, como el control biológico, que permite la producción sostenible de los cultivos de brasicáceas. La industria agrícola y forestal reconoce a la bacteria entomopatógena Bacillus thuringiensis (Bt) como una buena alternativa biológica a los insecticidas químicos, 
puesto que es inocua sobre el ambiente y su toxicidad es altamente selectiva, ligada a su estrecho rango de especificidad sobre diferentes insectos plaga de los órdenes Lepidóptera, Coleóptera y Díptera. En esta revisión se presentan las posibilidades actuales que se pueden emplear para el control de la $P$. xylostella utilizando modelos investigativos basados en ensayos biológicos con Bt. Dichas posibilidades buscan superar las desventajas existentes en relación con la plaga $P$. xylostella y los cultivos de brasicáceas, además de entender la fisiología de $B t$ bajo condiciones que permitan incrementar la eficacia en el control biológico.

Palabras clave: manejo integrado de plagas, insecticidas químicos, toxinas Cry, mortalidad, LC $_{50}$.

\section{ABSTRACT}

Plutella xylostella (L.) is an insect pest that mainly affects the brasicaceae or crucifers crops such as cabbage, cauliflower, broccoli, radish, inter alia. The limitations of the yield and the quality of these crops, is mainly directed to the management of this pest. At present, for the control of $P$. xylostella is used insecticides of chemical synthesis, such as pyrethroids, carbamates, organophosphates, which have immediate action, but cause adverse effects on health and the environment. In addition, the absence of natural enemies capable of controlling populations and the ability to be resistant to conventional insecticides, causes this insect to establish quickly in brasicaceae producing areas. Currently, global costs associated with the control of $P$. xylostella, along with losses in agricultural production, are estimated between four and five billion dollars per year.

Safe and effective alternatives with less environmental impact such as biological control have been proposed, which allows the sustainable production of crucifers crops. The agricultural and forestry industry recognizes the entomopathogenic bacterium Bacillus thuringiensis $(B t)$ is the best biological option to insecticides, since it is innocuous to the environment and possesses a highly selective toxicity linked to its narrow range of specificity on different insects pest such as Lepidoptera, Coleoptera and Diptera. This review presents the possibilities that can be used for the control of $P$. xylostella using the models based on biological tests with $B t$. These possibilities seek to overcome the disadvantages that exist in relation to $P$. xylostella pest and the brasicaceas crops, besides understanding the physiology of Bt under conditions that allow to increase the effectiveness in the biological control.

Keywords: Integrated Pest Management, chemical insecticides, Cry toxins, mortality, LC $_{50}$.

\section{INTRODUCCIÓN}

Las crucíferas o brasicáceas son una familia de plantas de interés agrícola que incluye plantas cultivadas y silvestres de brócoli, coliflor, repollo, colza, mostaza y rábano, entre otras (Corpoíca, 1998). Durante la década del 2000, la producción mundial media estimada para estos cultivos fue de treinta millones de hectáreas (Zalucki, Shabbir, Silva, Adamson, Shu-Sheng y Furlong, 2012). La producción y el rendimiento de brasicáceas dependen y están limitados principalmente por la incidencia de plagas, entre las que se encuentran insectos coleópteros (Phyllotreta nemorum,
Harmonia conformis), áfidos (Brevicoryne brassicae, Lipaphis erysimi, Myzus persicae) y lepidópteros (Pieris spp., Crocidolomia binotalis, Hellula undalis y Plutella xylostella) (Srinivasan, Shelton y Collins, 2011).

La P. xylostella (Lepidóptera: Plutellidae) es la plaga más frecuente, destructiva e importante para el cultivo de brasicáceas a escala mundial (Shelton, Sances, Hawley, Tang, Boune, Jungers, Collins y Farias, 2000; Furlong, Wright y Dosdall, 2013). Las pérdidas ocasionadas por este insecto son inciertas. Sin embargo, Shelton, et al. (2000) predicen que podrían llegar a ser del $90 \%$, de acuerdo con las características ambienta- 
les del lugar de cultivo, el periodo de crecimiento y la frecuencia de aplicación de insecticidas. Es un insecto plaga de difícil manejo debido a que presenta resistencia a numerosos insecticidas (Tabashnik, Cushing y Johnson, 1987; Shelton, et al., 2000) y su potencial reproductivo va en aumento por la ausencia de enemigos naturales (Muñiz, Marí, Díaz, Gámez, Ávila, Herrera, Dorantes y Gámez, 2013). Es por esto que los agricultores prefieren utilizar insecticidas de síntesis química para controlarlo, ya que tienen un efecto knock-down inmediato y se encuentran fácilmente en el comercio local. En general, estos insecticidas son altamente tóxicos para la salud humana y el medio ambiente. Por ejemplo, los insecticidas que contienen metil paratión, malatión, endosulfán, carbaril, dimetoato y metamidofos son de uso corriente en cultivos de repollo en Tailandia (Panuwet, Siriwong, Prapanontol, Ryan, Fiedler, Robson y Boyd, 2012) y son productos que están prohibidos en varios países, y están clasificados por la Organización Mundial de la Salud como sustancias extremadamente peligrosas (1a) y altamente peligrosas (1b) (OMS, 1996). El abuso de este tipo de insecticidas en la producción de brasicáceas plantea riesgos asociados con fenómenos de resistencia, como es el caso de poblaciones de P. xylostella recolectadas en cultivos de crucíferas en Brasil, que mostraron una resistencia significativa a los insecticidas abamectina (Vertimec ${ }^{\circledR}$ ), metomil (Lannate ${ }^{\circledR}$ ), lufenurón (Match ${ }^{\circledR}$ ), indoxacarb (Steward ${ }^{\circledR}$ ) y diafentiuron (Polo ${ }^{\circledR}$ ) (Santos, Siquiera, da Silva y de Farias, 2011). Adicionalmente, el riesgo que representan los insecticidas de síntesis química para la salud de los productores, consumidores y el medio ambiente ha generado un creciente interés en las técnicas de manejo integrado de plagas (MIP) contra la $P$. xylostella (Srinivasan, et al., 2011).

El control biológico es uno de los principales componentes del MIP, que utiliza enemigos naturales para el manejo de plagas agrícolas. Actualmente, debido a la grave amenaza que representa la $P$. xylostella para los cultivos de crucíferas, se ha incrementado el interés por adoptar herramientas amigables con el medio ambiente y la salud humana. Se ha fomentado el uso de bioinsecticidas, principalmente fórmulas que contienen la bacteria entomopatógena $\mathrm{Ba}$ - cillus thuringiensis $(B t)$, compuestas principalmente de mezclas de esporas y cristales derivados de la actividad biológica específica de $B t$ var. aizawai HD137 (XenTari ${ }^{\circledR}$ WG) (que sintetiza las proteínas Cry1Aa, Cry1Ab, Cry1Ac, Cry2A y Cry2B) y Bt var. kurstaki HD1 (Dipel ${ }^{\circledR}$ ) (que sintetiza las proteínas Cry1Aa, Cry1Ab, Cry1C y Cry1D y Cry2B), que han conducido al uso racional de insecticidas de síntesis química en México y a la reducción significativa del uso de estos en países del sudeste asiático, como Indonesia, Malasia, Filipinas y Tailandia (Srinivasan, et al., 2011). Al mismo tiempo, se ha requerido que otras organizaciones a escala mundial, como la Organización de las $\mathrm{Na}$ ciones Unidas para la Agricultura y la Alimentación (FAO, 2005), desarrollen y fomenten un control eficaz, sostenible y económicamente rentable de la $P$. xylostella, dado que los costos del control y las pérdidas de producción, si no se aplican estrategias de manejo integrado, se estiman en billones de dólares anuales en todo el mundo (Zalucki, et al., 2012), lo que convierte a la $P$. xylostella en la plaga más importante para el cultivo de brasicáceas (Furlong, et al., 2013).

\section{PLUTELLA XYLOSTELLA Y LOS CULTIVOS DE BRASICÁCEAS}

Los cultivos de brasicáceas o crucíferas como el repollo (Brassica oleracea var. capitata), coliflor (B. oleracea var. botrytis), brócoli (B. oleracea var. italica), rábano (Raphanus sativus), nabo ( $B$. rapa pekinensis), col de bruselas (B. oleracea var. gemmifera), repollo chino (B. rapa var. pekinensis), mostaza (B. juncea) y colza (B. napus), entre otras, se encuentran extensamente distribuidos en el mundo (Srinivasan, et al., 2011). El brócoli y la coliflor representan una importante fuente de divisas y significativos beneficios para los productores de México (Muñiz, Marí, Díaz, Gámez, Ávila, Herrera, Dorantes y Gámez, 2013) y de otros países. Las limitaciones del rendimiento y calidad de estos cultivos se deben en gran medida a la $P$. xylostella y su capacidad de resistencia a numerosos insecticidas de origen químico convencionales, tales como el DDT (Digmar ${ }^{\circledR}$ ), diazinón (Basudin ${ }^{\circledR}$ ), permetrina (Depe ${ }^{\circledR}$ ), fenvalerato (Fenkill ${ }^{\circledR}$ ) (Tabashnik, et al., 1987; Shelton, et al., 2000); deltametrina (Decis ${ }^{\circledR}$ Forte $10 \mathrm{EC}$ ) (Rosa, Araya, Guerrero y Lamborot, 
1997); clorantraniliprol (Rynaxypyr ${ }^{\circledR}$ ), flubendiamida (Belt ${ }^{\circledR}$ SC) (Wang, Khakame, Ye, Yang y Wu, 2012); abamectina (Vertimec ${ }^{\circledR}$ ) (Wang y Wu, 2014; Xia, Lu, Shen, Gao, Qiu y Li, 2014; Wang, Wei, Zhu y Zhou, 2015); spinosad (Tracer ${ }^{\circledR}$ ), clorfluazuron (Ishipron $\left.{ }^{\circledR}\right)$, indoxacarb (Steward ${ }^{\circledR}$ ), beta-cipermetrina (Sipertrin ${ }^{\circledR}$ ) (Xia, et al., 2014; Jiang, Wu, Yang, Zhu y Gao, 2015; Wang, et al., 2015); clorfenapir (Sunfire ${ }^{\circledR} 24$ SC) (Jiang, et al., 2015; Wang, et al., 2015) y benzoato de emamectina (Proclaim ${ }^{\circledR}$ Forte) (Wang, et al., 2015). Dicha resistencia prevalece sobre todo en las regiones tropicales y subtropicales, donde la producción de cultivos es prácticamente continua. En Malasia, más del $90 \%$ de los agricultores emplean entre tres y cuatro tipos de insecticidas químicos durante 10-12 semanas, con una frecuencia de una a dos veces por semana (Furlong, et al., 2013). Esto, unido a la ausencia de enemigos naturales en los cultivos de crucíferas, hace que la $P$. xylostella se establezca rápidamente en áreas productoras o emigre a nuevas zonas para aumentar su potencial reproductivo (Muñiz, et al., 2013), para así alcanzar hasta el $75 \%$ de la población total de insectos en los cultivos (Shelton, et al., 2000).

El potencial reproductivo de la $P$. xylostella está determinado principalmente por el entorno ambiental para desarrollar su ciclo de vida en 32 días, desde huevo hasta adulto, pasando por larva y pupa. Las hembras eligen sitios de ovoposición adecuados y asociados a condiciones de temperatura y humedad favorables, y a estímulos visuales, físicos y químicos provenientes de las plantas (Sarfraz, Dosdall y Keddie, 2006; Dosdall, 2014). Entre las etapas del ciclo de vida, el primer estadio larval de la $P$. xylostella es el que produce el mayor impacto sobre las plantas crucíferas. En este estadio, las larvas penetran y se alimentan del tejido de las hojas, mientras que, en los estadios posteriores, las larvas se alimentan en la superficie de hojas, brotes, flores y vainas. Cabe señalar que, por las condiciones de temperatura y humedad de los trópicos, en épocas secas, los daños que produce este insecto se acentúan debido a la ausencia de lluvias que podrían arrastrar las larvas fuera de los cultivos (Ibiza, 2015), por lo que pueden completar varios ciclos de vida de forma continua.
El primer reporte del costo anual del control de la $P$. xylostella en la agricultura fue estimado en un billón de dólares por Talekar y Shelton (1993). Actualmente se tiene como referente el resultado presentado por Zalucki, et al. (2012), quienes calculan que los costos mundiales asociados a este proceso, sumados a las pérdidas de producción, representan entre cuatro y cinco billones de dólares anuales. El control de esta plaga, que depende en gran medida de aplicaciones de insecticidas de síntesis química, constituye, por tanto, el mayor costo fijo en la producción agrícola de brasicáceas a escala mundial. Una herramienta fundamental para el control de los cultivos es el manejo integrado de plagas (MIP), debido a que propone alternativas que no se limitan al uso de insecticidas, sino que combinan herramientas como labores culturales, mecánicas o biológicas, tales como saneamiento vegetal, riego, rotación de cultivos y control biológico (Navarro, 2010). Este último corresponde al uso de organismos vivos o sus productos, con el fin de reducir las poblaciones de organismos plaga para aminorar sus efectos perjudiciales en los cultivos (López Pazos, 2011).

Existe una diversidad de organismos patógenos asociados al control de insectos plaga, entre los que se encuentran bacterias, hongos, protozoarios, nematodos y virus (Muñiz et al., 2013). A pesar de que estos se han identificado como organismos que conservan el equilibrio natural en el agroecosistema, representan únicamente una demanda de us 0.63 billones en el mercado internacional anual, comparada con US 25.3 billones por uso de insecticidas de síntesis química (Ibrahim, Griko, Junker y Bulla, 2010). Entre los patógenos de insectos plaga más utilizados en la entomología económica, la bacteria Bacillus thuringiensis es el agente de control más común (Hernández Fernández, 2016).

\section{BACILLUS THURINGIENSIS}

El Bacillus thuringiensis (Bt) es una bacteria en forma de bacilo, grampositiva, aeróbica facultativa, quimioorganótrofa, con actividad catalasa y formadora de esporas. Su tamaño oscila entre 1 y $1.2 \mu \mathrm{m}$ de ancho y 3 a $5 \mu \mathrm{m}$ de largo (Gordon, Haynes y Pang, 1973; 
Hernández Fernández y López Pazos, 2011). El Bt es considerado una bacteria ubicua, ampliamente distribuida, que se ha aislado en diferentes ambientes, como el suelo, el agua dulce, alimentos, cadáveres de insectos, anélidos, crustáceos, mamíferos insectívoros y ecosistemas de manglar (Hernández Fernández, 2016). Pertenece al orden Eubacterias, familia BaciIlaceae, grupo I del género Bacillus (Hofte y Whiteley, 1989; Porcar y Juárez Pérez, 2004). Se diferencia de otras especies de su género por producir un cuerpo o inclusión paraesporal, conocido como cristal, durante su fase de esporulación, que tiene propiedades insecticidas específicas contra ciertos órdenes de insectos, y resulta del ensamblaje de unidades polipeptídicas (denominadas delta endotoxinas) de diferentes pesos moleculares que oscilan entre 27 y 140 kDa (Schnepf,
Crickmore, Van Rie, Lereclus, Baum, Feitelson, Zeigler y Dean, 1998; Hofte y Whiteley, 1989). Los cristales tienen diversas formas: bipiramidal, cuboidal, romboide, oval, esférica, plana o, en algunos casos, sin forma definida, y son refringentes al microscopio de contraste de fases (Porcar y Juárez Pérez, 2004; Soberón y Bravo, 2007; Hernández Fernández, 2016) (figura 1). Diferentes estudios han determinado asociaciones entre la morfología del cristal, sus proteínas Cry constituyentes, el peso molecular de estas y su espectro de actividad insecticida. Sin embargo, también existen trabajos en los que se describen cristales paraesporales que, a pesar de tener morfologías asociadas a una toxicidad específica, no parecen tener actividad insecticida alguna (López Meza e Ibarra, 1996; Benintende, López Meza, Cozzi, e Ibarra, 1999).

Figura 1. Micrografía electrónica de esporas de B. thuringiensis (a) y de proteínas Cry purificadas (b y c). sp, espora; c, crystal
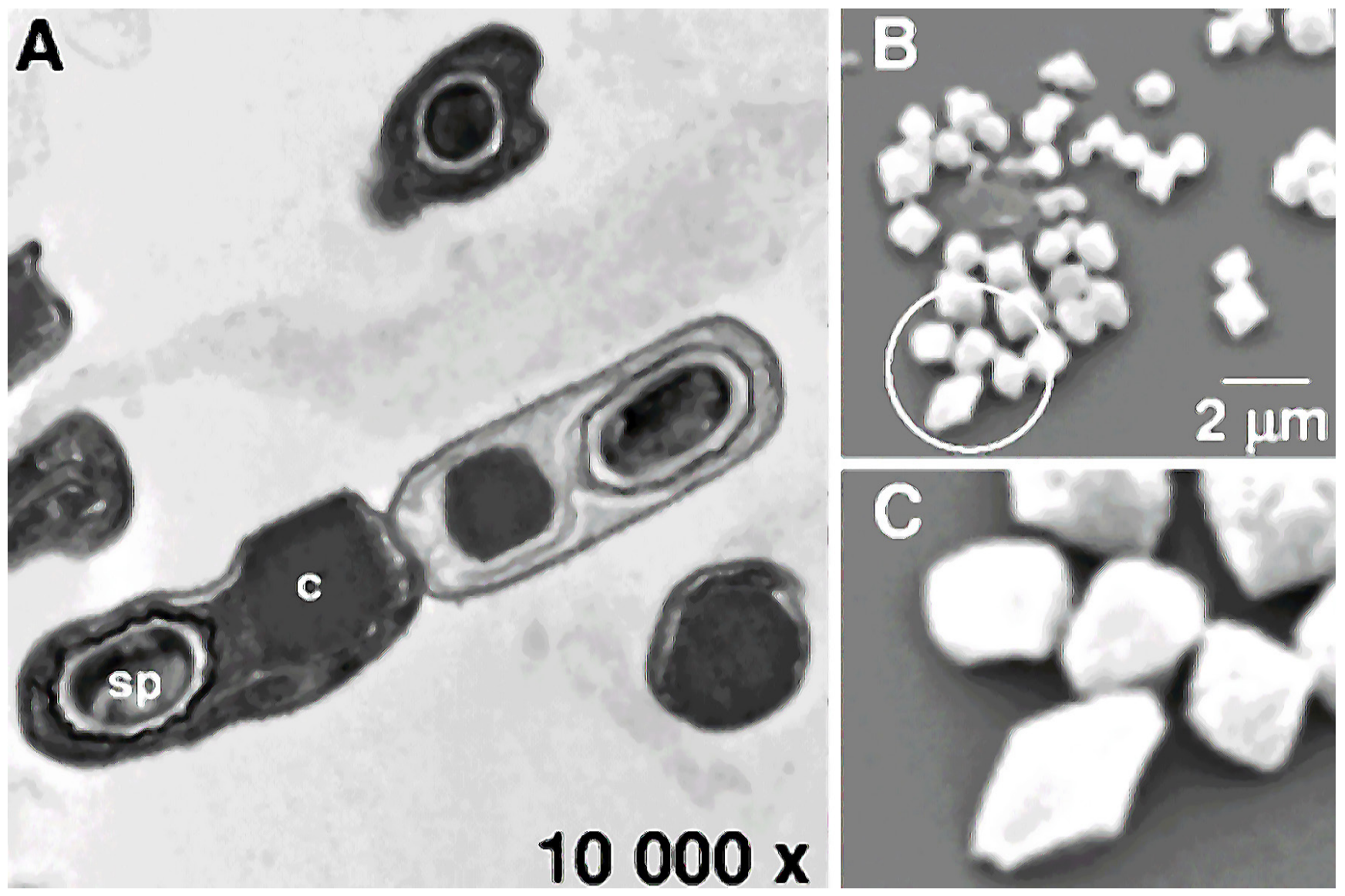

Fuente: Swiecicka, Bideshi y Federeci, 2008. DoI: http://dx.doi.org/10.1128/AEM.01955-07 
El esfuerzo continuo de varios países para aislar y caracterizar nuevas cepas de $B t$ y proteínas Cry ha producido, en la actualidad, el conocimiento de una mayor variedad de genes cry (981 en total), clasificados en 73 familias (cry1-cry73) de acuerdo con su secuencia primaria de aminoácidos (Crickmore, Baum, Bravo, Lereclus, Narva, Sampson, Schnepf, Sun, y Zeigler, 2016, http://www.btnomenclature.info/). Las proteínas codificadas presentan una identidad aminoacídica que puede variar desde $20 \%$ hasta $90 \%$ (Sauka y Benintende, 2008), lo que demuestra su gran variabilidad genética. Los genes cry tienen una secuencia codificante compuesta por entre 1900 y 3600 pares de bases (pb) (Crickmore et al., 2016), que determinan la toxicidad sobre larvas de insectos plaga de los órdenes Lepidóptera, Coleóptera y Díptera, principalmente (van Frankenhuyzen, 2009). La mayoría de los genes cry que se conocen pertenecen al grupo cry1, y su actividad corresponde específicamente al orden Lepidóptera. Estos genes codifican proteínas de entre 70 y 130 kDa, aproximadamente, y durante la esporulación se agrupan principalmente en cristales bipiramidales (Roh, Choi, Li, Jin y Je, 2007). Además, 278 genes cry 1 están descritos y clasificados en 14 clases (desde A hasta N) (Crickmore et al., 2016). De estas clases, el gen cry $1 A$ es el que se detecta con mayor frecuencia; otros, como los genes cry $1 B$, cry $1 C$ y cry $1 D$, se encuentran menos frecuentemente, en tanto que genes como $\mathrm{cry} 1 \mathrm{H}, \mathrm{cry} 1 \mathrm{~K}$, cry $1 L$ y cry $1 N$ son muy raros en la naturaleza (Sauka y Benintende, 2008). La frecuencia de detección de los distintos genes cry varía en forma marcada, y esto depende en parte del modo de acción de las toxinas Cry y la estructura tridimensional de las proteínas.

\section{ESTRUCTURA TRIDIMENSIONAL DE LAS TOXINAS CRY}

La estructura tridimensional de las toxinas Cry está compuesta por tres dominios funcionales. El dominio I está conformado por un paquete de siete alfahélices antiparalelas (hidrófobas e hidrófilas), en las que seis hélices hidrófilas rodean a la quinta hélice hidrófoba (figura 2). Cada una de las hélices hidrófilas presenta residuos polares en la cara externa, mientras que los residuos hidrófobos se orientan hacia la alfa hélice central (De León, 2010). Se considera que este dominio está involucrado en la formación del poro e inserción en la membrana en el epitelio intestinal del organismo susceptible (Hernández Fernández y López Pazos, 2011; Bravo, Gómez, Porta, García Gómez, Rodríguez Almazán, Pardo y Soberón, 2012). El dominio II es el más variable, ya que conserva en menor grado la secuencia y estructura terciaria entre las toxinas Cry (De Maagd, Bravo y Crickmore, 2001). Está conformada por tres hojas plegadas antiparalelas $\beta$ y por tres asas distribuidas en una topología tipo "Ilave griega" (figura 2) (Hernández Fernández y López Pazos, 2011; Bravo et al., 2012). En las asas de sus hojas plegadas $\beta$ se observa la mayor diferencia estructural (De León, 2010). Las asas de este dominio presentan similitud con los sitios de unión antígeno-anticuerpo, y juegan un papel fundamental en la especificidad de la toxina. Es en la sección de las asas donde se reconoce el receptor que se encuentra en las microvellosidades de las células epiteliales del intestino medio del organismo susceptible (De León, 2010). El último dominio funcional consiste en dos láminas plegadas $\beta$ antipa-

Figura 2. Estructura general de las toxinas Cry de tres dominios. Los dominios I, II y III se muestran en rojo, verde y azul, respectivamente
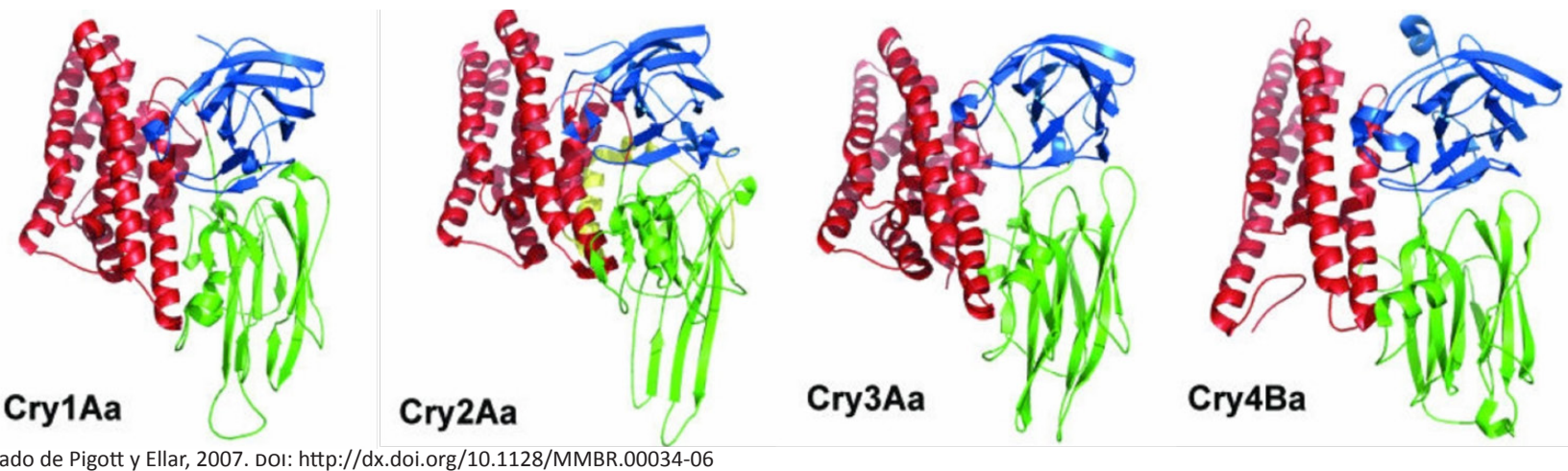

Adaptado de Pigott y Ellar, 2007. DoI: http://dx.doi.org/10.1128/MMBR.00034-06 
ralelas (figura 2), que forman un $\beta$-sándwich, y está involucrado en el mantenimiento de la integridad estructural de la toxina ante la proteólisis en el intestino del organismo susceptible. Participa en la interacción con receptores presentes en el epitelio intestinal del insecto blanco, en la penetración en la membrana celular y en la formación de canales iónicos que generan desbalance osmótico (Schnepf, et al., 1998; Bravo, et al., 2012; Hernández Fernández y López Pazos, 2011).

\section{MECANISMO DE ACCIÓN DE LAS TOXINAS CRY}

El modelo que mejor explica el modo de acción de las toxinas Cry en lepidópteros es el de Bravo et al. (2012), en el que las proteínas Cry son sintetizadas como una protoxina que se cristaliza para formar inclusiones proteicas. Cuando una larva de insecto susceptible ingiere las esporas y los cristales de $B t$, estos se solubilizan en el intestino medio del insecto, debido al ambiente alcalino que rompe los enlaces disulfuro (determinantes de la toxicidad de la proteína
Cry), y facilitan la liberación de las protoxinas. Estas protoxinas son estimuladas por proteasas (tripsinas o quimotripsinas) que provocan cortes en la molécula, dejando una toxina de tres dominios completamente activada con un tamaño molecular aproximado de 55 a $65 \mathrm{kDa}$. La toxina tiene alta afinidad con receptores específicos, y reconoce especialmente un receptor primario tipo cadherina (CADR: glicoproteína) en las microvellosidades celulares del intestino del insecto susceptible, que interactúa con la toxina Cry y provoca un cambio conformacional en la proteína, lo que facilita la oligomerización y la formación de un preporo. De acuerdo con Bravo, et al. (2012) y Pigott y Ellar (2007), una vez formado el preporo, este tiene alta afinidad con receptores secundarios de la membrana apical, como las $\mathrm{N}$ aminopeptidasas (APN), alcalino fosfatasas (ALP) y glicolípidos que interactúan en regiones específicas de la membrana y facilitan la formación de poros líticos. Estos últimos permiten el paso de iones, agua y la germinación de esporas, lo que causa hinchazón, lisis y finalmente septicemia del hospedero (figura 3 ).

Figura 3. Modo de acción del B. thuringiensis sobre insectos Lepidóptera. 1) Ingestión de bacterias, 2) solubilización de los cristales, 3) activación de la proteína, 4) unión de proteínas a los receptores, 5) formación de poros en la membrana y lisis celular

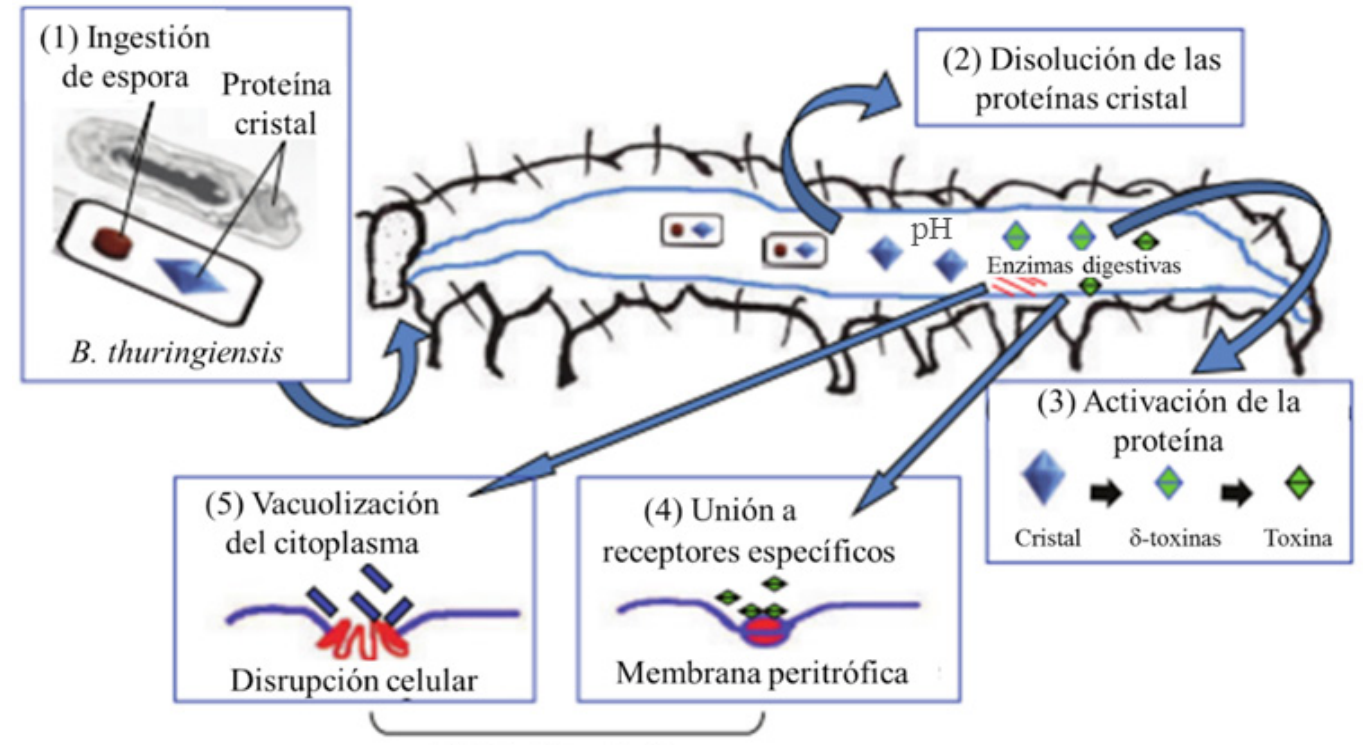

Células intestinales 


\section{EL BACILLUS THURINGIENSIS Y CONTROL DE LA PLUTELLA XYLOSTELLA}

El $B t$ se considera un entomopatógeno de relevancia, debido a que produce una gran diversidad de proteínas Cry que presentan un alto grado de plasticidad y variabilidad genética (Schnepf, et al., 1998) con potencial y amplias perspectivas para el control biológico de insectos plaga a escala mundial (Hernández Fernández y López Pazos, 2011).

A partir del conocimiento descrito y la aplicación de la tecnología del ADN recombinante se ha conseguido (usando varios hospederos de expresión) la clonación, purificación y expresión de nuevas proteínas Cry. Además, se ha logrado determinar la actividad tóxica de estas proteínas sobre varias especies de insectos lepidópteros, coleópteros y dípteros plaga. En este contexto, Pan, Xu, Zhu, Shi, Chen y Liu (2014) aislaron y caracterizaron el gen cry $2 A b 3$ que identificaron en la cepa nativa $B t$ FJAT-12 en Fujian, China. Ellos clonaron y expresaron el gen en Escherichia coli $\mathrm{DH} 5 \alpha$ y E. coli BL21 y evaluaron la actividad insecticida de la proteína transformada contra la $P$. xylostella, y produjeron una concentración letal $50\left(\mathrm{LC}_{50}\right)$, de $1,03 \times 10^{-5} \mu \mathrm{g} \cdot \mathrm{ml}^{-1}$.

Dai, Su, Jin, Zhang, Guan, Chen, Shu y Huang (2016) clonaron, expresaron y purificaron el gen cry1 Na3 de Bt BCR-ZYR2 a partir de datos y análisis genómicos previamente obtenidos. Su evaluación demostró que esta proteína es tóxica sobre larvas de la $P$. xylostella con una $\mathrm{LC}_{50}$ de 3,69 $\mu \mathrm{g} \cdot \mathrm{ml}^{-1}$. Además, el estudio evidenció que esta toxina también afecta a otras plagas de importancia económica, como la Ostrinia furnacalis (lepidóptera), Spodoptera exigua (lepidóptera), ColapheIlus bowringi (coleóptera) y Laodelphax striatellus (hemíptera). Los valores de la $\mathrm{LC}_{50}$ fueron $31,3,500,500$ y $250 \mu \mathrm{g} \cdot \mathrm{ml}^{-1}$, respectivamente, sobre estos insectos.

Los estudios descritos dejan en claro que el aislamiento e identificación de cepas bacterianas posibilitan la formulación de nuevos bioinsecticidas. En ese sentido, Chen, M., Chen, P., Pang, Lin, Hwang y Tsen (2014) obtuvieron 60 cepas (Bt TT1-тT62) que fueron aisladas de suelos y graneros en Taiwán. Posteriormente identificaron, caracterizaron y diferenciaron dichas cepas con los métodos RAPD y PFGE, que a su vez permitieron determinar la presencia o ausencia de 13 genes Cry seleccionados previamente con posible actividad la P. xylostella (Cry1, Cry1B, Cry1E, Cry2Aa1, Cry3A, Cry4A2, Cry7, Cry8D, Cry9A, Cry9C, Cry9Ea, Cry22 y Cry32Aa). Luego, en cada una de las cepas de $B t$ determinaron la concentración de las proteínas y evaluaron su actividad insecticida en larvas de tercer estadio de la P. xylostella. Para cada cepa de $B t$ fueron evaluados tres tiempos de incubación (24, 48 y 72 horas) con dos dosis de concentración de proteína ( $25 \mathrm{mg} . \mathrm{L}^{-1}$ y $250 \mathrm{mg} . \mathrm{L}^{-1}$ ). Los resultados demostraron tasas de mortalidad mayores al $90 \%$ en las cepas TT35, TT46 y TT46 con la concentración de 250 mg. L $^{-1}$ después de 24,48 y 72 horas, respectivamente. Por el contrario, con la concentración de 25 mg. $\mathrm{L}^{-1}, 19$ cepas mostraron mayor actividad que las cepas de referencia (TT12 y TT13) después de 24 horas de aplicado el tratamiento. De igual forma, los autores determinaron que la mortalidad de las larvas aumentó gradualmente con la duración del tiempo de incubación. Por otro lado, seleccionaron 29 cepas al azar para identificar la presencia o ausencia de los 13 genes seleccionados previamente y encontraron que ninguna de las 29 cepas contenía los genes $\mathrm{Cry} 1 \mathrm{E}, \mathrm{Cr}$ y3A, Cry4A2, Cry8D, Cry9A, Cry9C y Cry32Aa. Ellos haIlaron que la presencia de los genes Cry2Aa1 y Cry9Ea se correlacionó positivamente con la actividad insecticida de las cepas de $B t$ sobre la P. xylostella a las 24, 48 y 72 horas de incubación. Es decir, la presencia de estos genes tuvo un mayor efecto sobre la $P$. xyloste$I l a$, y pueden ser utilizados como referencias para predecir la actividad insecticida contra este insecto plaga. Cabe señalar que todas las cepas seleccionadas al azar fueron positivas para la presencia de genes Cry1, con la diferencia de que cinco cepas (TT 12, 30, 48, 50 y 59) exhibieron altos niveles de actividad insecticida ( $60 \%$ a $80 \%$ con 25 mg. L $^{-1}$ de proteína) debido a que mostraron sobresalientes niveles de expresión de dicho gen comparado con nueve cepas (TT 3, 4, 11, 19, $23,47,49,56$ y 57 ) que mostraron bajos niveles de expresión del gen Cry1 y mostraron bajos niveles de actividad insecticida. Estos resultados demostraron que cepas con altos niveles de expresión del gen Cry 1 tienen significativamente mayor actividad insecticida contra la $P$. xylostella que aquellos con bajos niveles de expresión de este gen. Además, esto implica que el 
alto nivel de expresión de los genes Cry1 desempeña un papel clave para determinar la actividad insecticida de las cepas Bt contra larvas de la P. xylostella.

Rekha, Srinivasan, Kumar, Bharpoda y Cgatterjee (2011) realizaron un bioensayo en el que determinaron la susceptibilidad de las toxinas Cry1Ac, Cry1Ba2 y Cry1Ca4 sobre larvas de la P. xylostella. En todos los casos la susceptibilidad de este insecto ante las tres toxinas fue alta. $\mathrm{La} \mathrm{CL}_{50}$ de las toxinas Cry1Ac, Cry1Ba2 y Cry1Ca4 fue de 0.06-0.10 $\mu \mathrm{g} \cdot \mathrm{ml}^{-1}, 0.08-0.09 \mu \mathrm{g} \cdot \mathrm{ml}^{-1}$ y 0.06-0.09 $\mu \mathrm{g} \cdot \mathrm{ml}^{-1}$, respectivamente. Finalmente, los autores sugirieron que las poblaciones de la $P$. xylostella pueden ser controladas usando formulaciones comerciales de $B t$ que contengan cualquiera de estas toxinas Cry.

Legwaila, Munthaili, Kwerepe y Obopile (2015) realizaron un bioensayo para determinar la $L_{50}$ y $L_{90}$ de $B t$ var. kurstaki (Btk) frente a huevos y larvas de segundo estadio de la P. xylostella, en Gaborone, Botsuana. Utilizaron seis tratamientos bajo condiciones de invernadero (semicontroladas) que comprendían cinco concentraciones de Btk Vectobac ${ }^{\circledR}(2,4,6,8$ y 10 g.L. L $^{-1}$ de agua) y un control de agua destilada. En cada tratamiento se utilizaron nueve plántulas de repollo previamente adaptadas en jaulas de cría. Posteriormente, sobre dichas plántulas, en las que había entre 50-70 huevos (c/u) y 30-40 larvas (c/u), se pulverizaron las concentraciones del producto. Los huevos ovipositados en cada planta se contaron inmediatamente antes de la aplicación de los tratamientos, y se recontaron a las 48,72 y 96 horas, mientras que las larvas se evaluaron a intervalos de $24,48,72,96$, 120 y 144 horas después de aplicado el tratamiento. Los resultados indicaron que $l_{a} L_{50}$ y $L_{90}$ de $B t k$ frente a huevos de la $P$. xylostella cuando se evaluaron 48 horas después de la incubación fueron de 3,79 y 7,71 g. $\mathrm{L}^{-1}$, respectivamente. Cuando la evaluación se realizó 72 horas después del período de incubación, los valores de $L_{50}$ y $L_{90}$ de Btk disminuyeron a 2,60 y 6,94 g. $\mathrm{L}^{-1}$, respectivamente. Asimismo, los valores 96 horas después de aplicado el tratamiento fueron de 1,75 y $6,24 \mathrm{~g} . \mathrm{L}^{-1}$, respectivamente. Esto demuestra que la mortalidad promedio de huevos de la $P$. xylostella por planta fue significativamente afectada por las concentraciones de $B t k$ y el período después de la aplicación (Anova, $P<0,05 \%$ ). Por otro lado, la mayor mortalidad de huevos (100 \%) ocurrió en plantas tratadas con dosis de 8 y 10 g. $\mathrm{L}^{-1}$ evaluadas 48 horas después, mientras que la más baja ( $24 \%$ ) fue de plantas tratadas con 2,0 g. $\mathrm{L}^{-1}$ en el mismo período de incubación (Tukey $P=0,05$ ). En cuanto a las larvas en segundo estadio de la $P$. xylostella, los resultados indican que el insecticida $B t k$ no alcanzó la mortalidad larvaria del 50 \% 24 horas después de la aplicación en todas las concentraciones, mientras que, cuando se evaluaron después de 48 y 72 horas, fue de 6,71 y 3,07 g.L. L $^{-1}$, respectivamente. Asimismo, los valores de $\mathrm{LD}_{90}$ registrados con la aplicación de Btk cuando se evaluaron a $72,96,120$ y 144 horas fueron de 11,02, 10,22, 5,92 y 4,01 g. L $^{-1}$, respectivamente. Los autores demuestran con estos resultados que tanto la concentración como el periodo de incubación después de la aplicación del producto afectaron significativamente la mortalidad media de las larvas por planta (Anova, $P<0,05 \%$ ). Ellos señalan que la mayor mortalidad $(90,8,92,3$, 93,0 y 93,3 \%) ocurrió 144 horas después de la aplicación de soluciones Btk en concentraciones de 4,0, 6,0, 8,0 y 10,0 g. L $^{-1}$, respectivamente. La menor mortalidad (0.0-26.7 \%) se produjo en el tratamiento control durante todo el período de estudio (Tukey $P=0,05$ ). Cabe anotar que el nivel de mortalidad que resultó en una protección eficaz de las plantas de repollo requirió una dosis superior a la dosis recomendada de Btk $\left(4,0 \mathrm{~g} \cdot \mathrm{L}^{-1}\right)$. Estos resultados sugieren que el uso de dosis más altas a las recomendadas de Btk bajo condiciones de invernadero (semicontroladas) en los programas de control podría reducir lo suficiente las poblaciones de la $P$. xylostella y evitar la necesidad de repetir las aplicaciones en el año siguiente.

Otros autores determinaron que la combinación de dos o más proteínas insecticidas de $B t$ sin resistencia cruzada y con sitios independientes de acción puede ser una estrategia para aumentar la actividad tóxica de $B t$ sobre poblaciones de insectos plaga o para retrasar el desarrollo de poblaciones de insectos resistentes (Head y Greenplate, 2012). En este contexto, Lira, Beringer, Burton, Griffin, Sheets, Yee, Woosley, Worden y Narva (2013) evaluaron la actividad insecticida de la proteína Cry1Bh1 de la cepa Bt PS46L contra larvas resistentes de primer estadio de $P$. xylostella, Ostrinia nubilalis, Heliothis virescens, Helicoverpa zea, 
Diabrotica virgifera y Spodoptera frugiperda. Además, evaluaron la actividad insecticida de la unión de Cry1Bh1-Cry1Ab y Cry1Bh1-Cry1Fa contra larvas de último estadio de $O$. nubilalis. Estos autores demostraron una acción del $100 \%$ de mortalidad en larvas de $P$. xylostella y $H$. virescens, $69 \%$ en larvas de $O$. nubilalis, un efecto insignificante sobre larvas de $H$. zea y $D$. virgifera, y una acción nula sobre larvas de $S$. frugiperda.

La resistencia desarrollada por la $P$. xylostella ha llevado a la investigación a descubrir nuevas proteínas insecticidas activas oralmente, así como a evaluar los efectos combinados de $B t$ y otros organismos con el fin de retrasar y combatir la propagación de este insecto plaga (Nangong, Wang, Song, Hao, Yang y Wang, 2016). Nangong, et al. (2016) evaluaron mediante $\mathrm{CL}_{50}$ el daño combinado y separado de las bacterias Xenorhabdus nematophila ( $X n$ HB310), Bt HD-1 y $B t$ HD-73 sobre poblaciones de la P. xylostella. Para ello, obtuvieron de la Universidad Agrícola de Hebei, de China, tres cepas de las bacterias: $X$. nematophila ( $X n$ HB310), Bt HD-1 (que contiene los genes Cry1Aa, Cry1Ab, Cry1Ac, Cry1la, Cry2Aa, Cry2Ab y Vip3Aa) y $B t$ HD-73 (que contiene el gen $C r y 1 A c$ ). Posteriormente, obtuvieron y criaron en repollo chino larvas de tercer estadio susceptibles (sin ninguna exposición a insecticidas desde 150 generaciones anteriores) de la $P$. xylostella (DBM-S) y larvas de tercer estadio resistentes a Bt HD-73 (DBM-R), derivada de DBM-S en laboratorio (CAAS, China). Se realizaron dos bioensayos, en los que se prepararon diversas concentraciones de toxina de $B t$ HD-73 y Xn HB310. Para el primero usaron concentraciones de $B t$ HD-73 de 2,5, 5, 10,20 y $40 \mu \mathrm{g} \mathrm{ml}^{-1}$, a las cuales agregaron células de $X n$ HB310, mientras que el segundo ensayo tuvo seis concentraciones de $X n$ Hв310 $\left(2,24 \times 10^{6}, 7,47 \times 10^{5}\right.$, $2,49 \times 10^{5}, 8,29 \times 10^{4}, 2,77 \times 10^{4}$ y $9,22 \times 10^{3}$ UFC ml $^{-1}$ ), y se mezcló cada una con el fluido de la bacteria $B t$ HD73. Los resultados mostraron que la combinación de las tres bacterias $B t$ HD-73, Bt HD-1 y Xn HB310 fue tóxica para DBM-S y DBM-R, con $\mathrm{LC}_{50}$ de $0,49 \mu \mathrm{g} \cdot \mathrm{ml}^{-1}$ y $51,66 \mu \mathrm{g} \cdot \mathrm{ml}^{-1}$, respectivamente. Por otro lado, las $\mathrm{LC}_{50}$ únicamente de $B t$ HD-1 contra DBM-S y DBM-R fueron mucho mayores $\left(13,02 \mu \mathrm{g} \cdot \mathrm{ml}^{-1}\right.$ y $399,77 \mu \mathrm{g} \cdot \mathrm{ml}^{-1}$, respectivamente). Asimismo, las $\mathrm{LC}_{50}$ de $X n \mathrm{HB} 310$ contra

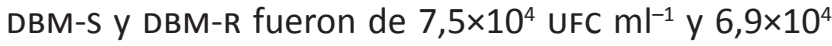
UFC $\mathrm{ml}^{-1}$. Estos datos demostraron que no existe resis- tencia cruzada entre las bacterias $X$. nematophila y $B t$. Pero también indican que la mezcla de $X n$ y $B t$ induce significativamente mayor mortalidad en comparación con el tratamiento por separado de la bacteria $X$. nematophila, lo que revela un efecto sinérgico de $B t$ sobre $X n$. Por otro lado, los resultados también demostraron el efecto sinérgico de cuatro combinaciones de Bt HD-73 en Xn HB310 en las larvas DBM-S y de cinco combinaciones en larvas DBM-R. Esto es significativo para Bt HD-73 en Xn HB310, pero no para Xn HB310 en $B t$ HD-73, lo que sugiere que es posible utilizar a $B t$ para mejorar la eficacia de $X n$. Finalmente, proponen que la mejor estrategia para retrasar el desarrollo de resistencia a plagas es emplear múltiples toxinas $u$ otras moléculas nuevas de diferentes organismos con modos alternativos de acción.

El uso de hongos entomopatógenos, insecticidas y la combinación de estos con el $B t$, también puede ser una opción viable para el control de larvas de la $P$. xylostella. Por ejemplo, Nian, He, Lu y Zhao (2014) realizaron bioensayos para evaluar la interacción entre las conidias aéreas de la cepa Isaria fumosorosea SCAU-IFCF01 y las dosis subletales $(222,5,445$ y $890 \mu \mathrm{g} \cdot \mathrm{ml}^{-1}$ ) de dos insecticidas: beta-cipermetrina (piretroide sintético) llamado comercialmente Luba-beta-cypermethrin, en formulación de concentrado emulsionable (EC), y Bt ssp kurstaki (Btk) (Hellafram, Grecia) en formulación de polvo humectable (WP) contra larvas de segundo estadio de la $P$. xylostella, mediante la respuesta de tiempo-concentración-mortalidad (TCM). Se realizaron siete bioensayos para evaluar la interacción entre I. fumosorosea y dosis subletales de los dos insecticidas contra larvas de la $P$. xylostella. Se hicieron suspensiones a partir de 0,03 g. $\mathrm{L}^{-1}$ de Tween-80 y suspensiones estandarizadas de $1 \times 10^{7}, 1 \times 10^{6}, 1 \times 10^{5}, 1 \times 10^{4}$ y $1 \times 10^{3}$ conidias $\mathrm{ml}^{-1}$ para cada bioensayo. Los resultados mostraron que, en todos los ensayos, las muertes de larvas causadas por micosis temprana comenzaron desde el primer o segundo día después de la exposición, y después hubo aumentos en la mortalidad de larvas de la $P$. xylostella. Además, demostraron que entre las seis combinaciones insecticida-hongo, todas las combinaciones de hongos e insecticidas tendieron a acelerar las muertes de la $P$. xylostella. Sin embargo, las diferencias de mortalidad entre los ensayos 
tendieron a disminuir a la concentración de hongos más alta $\left(1 \times 10^{7}\right.$ conidios $\left.\mathrm{ml}^{-1}\right)$ hacia el final de la observación. Por otro lado, determinaron que cuanto mayor era la dosis del insecticida que se incluía en las concentraciones del hongo, más se reducían las estimaciones de $\mathrm{LC}_{50}$; esto implica que el aumento de la dosis de insecticida (Bt o beta-cipermetrina), combinado con la virulencia fúngica mejorada de I. fumosorosea contra la $P$. xylostella se da mejores resultados. Finalmente, los autores señalan que las dosis subletales de la bacteria $B t$ y el insecticida beta-cipermetrina pueden sinergizar la actividad de la I. fumosorosea en la P. xylostella, y sugieren que la combinación de la $I$. fumosorosea con los dos insecticidas podría ofrecer un enfoque integrado para controlar la P. xylostella en la práctica.

Nian, He, Lu y Zhao (2015) determinaron la eficacia de dos formulaciones comerciales de conidias aéreas de la cepa Isaria fumosorosea SCAU-IFCF01 (polvo humectable: WP y aceite; OF) combinadas con Bt (Yangzhou Luyuan Bio-chemical Co., Ltd) sobre el segundo estadio larval de la $P$. xylostella. Se realizaron seis bioensayos para evaluar la interacción entre dos dosis subletales de $B t$ ( 223 y $668 \mu \mathrm{g} \cdot \mathrm{ml}^{-1}$ ) y las dos formulaciones fúngicas. Para la formulación WP se usó una concentración de $1 \times 10^{7}$ conidios $\mathrm{ml}^{-1}$ de polvo humectante de la cepa I. fumosorosea; a la vez, se hicieron diluciones en serie de $10^{3}-10^{6}$ conidios $\mathrm{ml}^{-1}$. Para la formulación OF, se diluyó el producto a $1 \times 10^{6}, 5 \times 10^{5}$, $1 \times 10^{5}, 5 \times 10^{4}$ y $1 \times 10^{4}$ conidios $\mathrm{ml}^{-1}$. Los resultados con ambas formulaciones, polvo humectante (WP) y aceite (OF), mostraron en todos los tratamientos que la aplicación combinada aumentó la mortalidad de las larvas de forma aditiva o sinérgica. Los efectos sinérgicos sobre la mortalidad fueron exhibidos en ambas dosis de $B t$ ( 223 y $668 \mu \mathrm{g} \cdot \mathrm{ml}^{-1}$ ), pero se observó principalmente en las aplicaciones combinadas con Bt 668 $\mu \mathrm{g} \cdot \mathrm{ml}^{-1}$. Por otro lado, cabe señalar que las larvas de la P. xylostella tratadas con la formulación a base de aceite murieron antes que las larvas tratadas con polvo humectable. Asimismo, las larvas tratadas tanto con la bacteria Bt como con la I. fumosorosea murieron antes que las larvas infectadas con uno solo de los patógenos. Finalmente, se señala que los tratamientos combinados de $B t$ con alta concentración de las dos formulaciones de la I. fumosorosea produjeron una mayor mortalidad larval $(84,4 \%$ y $86,2 \%$, respectivamente). Asimismo, los investigadores concluyen que la aplicación combinada de la I. fumosorosea y el $B t$ es una estrategia alternativa prometedora para el control de la P. xylostella.

Algunas especies son controladores biológicos de muy bajo costo de producción en laboratorio, son agresivas o presentan tolerancia a algunos plaguicidas sintéticos (Vacari, Otuka y de Bortoli, 2007), lo que es positivo para emplear tratamientos combinados. Podisus nigrispinus es una de ellas, y controla principalmente insectos lepidópteros plagas de cultivos, incluyendo a la $P$. xylostella. Magalhaes, Vacari, Laurentis, de Bortoli y Polanczyk (2014) determinaron mediante seis tratamientos la susceptibilidad de larvas de la P. xylostella a dos bioinsecticidas: la cepa HD1 de Bt (Bt var. kurstaki) y el producto comercial Agree ${ }^{\circledR}$ (Bt var aizawai CG 91). Además, evaluaron el impacto de estos bioinsecticidas en el consumo de larvas de segundo estadio de la $P$. xylostella en el insecto $P$. nigrispinus. Para ello se aplicó una alícuota de $2 \mathrm{ml}$ de la suspensión de $B t$ HD1 (Bt var. kurstaki) en una sola concentración $\left(3 \times 10^{8}\right.$ esporas. $\left.\mathrm{ml}^{-1}\right)$. Al mismo tiempo que la evaluación de la cepa HD1, se evaluó el producto comercial Agree ${ }^{\circledR}$ (Bt var aizawai CG 91$)$, aplicando la dosis recomendada por el fabricante $(0,5 \mathrm{~g} / 333 \mathrm{ml})$. Los resultados mostraron que tanto la cepa HD1 como el producto Agree causaron una mortalidad del $100 \%$ en las larvas de segundo estadio de la $P$. xylostella después de siete días de exposición. Sin embargo, la mortalidad registrada en el tratamiento de control fue solo del $12 \%$ (F2, $27=1233,77, \mathrm{P}<0,0001)$. Por otro lado, los depredadores mostraron un mayor número de eventos de alimentación en las hojas de col rizada cuando las larvas de la $P$. xylostella también estaban disponibles como presas. Tanto las ninfas como los adultos de $P$. nigrispinus consumieron mayor número de larvas de la $P$. xylostella y se alimentaron menos de hojas de col rizada cuando se asperjaron con la preparación de HD1 o el producto comercial Agree. Estos resultados sugieren una interacción positiva de los productos a base de $B t$ y el depredador $P$. nigrispinus en el control de las larvas de la $P$. xylostella. En conclusión, el uso de bioinsecticidas y la conservación de depredadores beneficiosos de la P. xylostella, como 
el controlador biológico $P$. nigrispinus, es un enfoque prometedor que tiene valor social y comercial.

La combinación de patógenos de insectos con insecticidas es una solución significativa para el control de plagas que aumenta los efectos de eliminar insectos susceptibles y reduce el uso de patógenos o pesticidas de origen químico (Nathan y Kalaivani, 2006). En ese sentido, la $P$. xylostella granulovirus ( $\mathrm{P} \times \mathrm{GV})$ y el Bt son ambos entomopatógenos de la $P$. xylostella (L.). Han, Li, Liu y Xu (2015) midieron mediante $\mathrm{LC}_{50}$ el efecto de la combinación de PXGV y Bt en dosis subletales sobre el desarrollo y la mortalidad de larvas de primer estadio hasta pupa de la $P$. xylostella recolectadas en plantaciones de repollo en Yangzhou (China). Así, se aplicaron diferentes concentraciones de $B t$ (de 0,625 a 40 ppm) o GV (de 102 a 109 cuerpos de oclusión. $\mathrm{ml}^{-1}$ ). Posteriormente, se midió la mortalidad larval por infección patógena cada 12 horas en cada tratamiento, hasta que todos los sobrevivientes llegaran a pupa. Los resultados demostraron que el tratamiento separado de $B t$ fue eficaz contra larvas de primer estadio de la $P$. xylostella. El valor de $\mathrm{LC}_{50}$ fue de 2,99 ppm. Tras el desarrollo de las larvas, el valor de $\mathrm{CL}_{50}$ fue aumentando: se incrementó a 11,66 ppm en las larvas de tercer estadio (casi cuatro veces mayor que el de las larvas del primer estadio). Por otro lado, los resultados también mostraron resistencia a la infección de PXGV en larvas de la $P$. xylostella, de acuerdo con el aumento del estadio larvario. Se encontró que las dosis de $\mathrm{LC}_{25}$ y $\mathrm{LC}_{50}$ de la PXGV fueron de $1,32 \times 10^{3}$ y $1,10 \times 10^{5}$ cuerpos de oclusión. $\mathrm{ml}^{1}$ en larvas de primer estadio, y aumentaron significativamente a $1,60 \times 10^{6}$ y $4,75 \times 10^{7}$ cuerpos de oclusión/ml en las larvas de tercer estadio, respectivamente, lo que significa una mayor mortalidad larvaria en comparación con el tratamiento por separado de $B t$ o PXGV. Además, cuando larvas de la $P$. xylostella consumían tanto $B t$ a la dosis de $\mathrm{LC}_{50}$ como a PXGV a la concentración de $\mathrm{LC}_{25}$, la mortalidad aumentó significativamente. Los autores concluyeron que la unión de $B t$ y PXGV exhibe un efecto sinérgico sobre la mortalidad de larvas de la $P$. xylostella y controla eficazmente las poblaciones de la misma con tratamiento combinado en dosis bajas. Sugieren también que la combinación de $B t$ y PXGV en dosis subletales podría proporcionar una valiosa manera de mejorar la eficacia de control de la $P$. xylostella en comparación con el tratamiento por separado de Bt o PXGV.

Diferentes entomopatógenos juegan un papel determinante en la reducción de poblaciones de insectos plaga bajo una estrategia óptima que no incluye el uso de insecticidas químicos que causan impacto y generan resistencia. Conte de Oliveira, Abreu de Siqueira, Vargas de Oliveira, Da Silva y Michereff (2011) estudiaron la susceptibilidad de ocho poblaciones brasileñas de la $P$. xylostella a los insecticidas abamectina (Streptomyces avermitilis), spinosad (Saccharopolyspora spinosa) y deltametrina (piretroide sintético). Después de 48 horas de exposición, encontraron una variación en la susceptibilidad a todos los insecticidas evaluados. Los valores de $\mathrm{LC}_{50}$ variaron desde 0,007 a $0,136 \mu \mathrm{g} \cdot \mathrm{ml}^{-1}$ para abamectina, 0.014 a 0.074 $\mu \mathrm{g} \cdot \mathrm{ml}^{-1}$ para spinosad y 85,19 a $360,10 \mu \mathrm{g} \cdot \mathrm{ml}^{-1}$ de deltametrina. Esto sugiere que los bioinsecticidas fueron más eficaces sobre las poblaciones brasileñas de la $P$. xylostella que el insecticida de origen químico. En definitiva, los avances recientes en el campo de la tecnología del ADN recombinante mantienen vigente el interés de lograr sistemas de expresión y cultivos bacterianos cada vez más eficientes para el mercado. Todas estas propuestas buscan superar desventajas existentes en relación con plagas agrícolas y entender la fisiología bacteriana bajo condiciones de producción que permitan incrementar la eficacia en el control del insecto plaga $P$. xylostella y generar nuevas opciones de procesamiento de proteínas recombinantes.

\section{CONCLUSIONES}

Las proteínas cry2Ab3, cry1Na3, cry2Aa1, cry9Ea y Cry1Bh1 pueden ser utilizadas como proteínas de referencia para predecir la actividad insecticida contra la $P$. xylostella, debido a sus sobresalientes niveles de expresión, que se correlaciona positivamente con la actividad biológica que tiene el Bt sobre este insecto plaga.

Se pueden usar formulaciones comerciales de $B t$ que contengan las toxinas Cry1Ac, Cry1Ba2 y Cry1Ca4, ya que necesitan bajas dosis de concentración para inducir mayor mortalidad contra el insecto plaga P. xylostella. 
La combinación de las bacterias Xenorhabdus nematophila y $B t$ es una opción viable para el control de larvas de segundo estadio de la P. xylostella debido a que induce mayor mortalidad, lo que revela un efecto sinérgico de $B t$ sobre $X$. nematophila, por lo que se recomienda utilizar a $B t$ para mejorar la eficacia de X. nematophila.

La combinación de conidias aéreas del hongo entomopatógeno Isaria fumosorosea e insecticidas como Bt var. kurstaki $(B t k)$ y beta-cipermetrina acelera la muerte de larvas de segundo estadio de la P. xylostella.

La $P$. xylostella es la plaga más frecuente, destructiva e importante para producción agrícola a escala mundial de especies de la familia Brassicaceae; por eso es necesario continuar con las investigaciones basadas en el aislamiento y caracterización de nuevas cepas nativas de $B t$, así como en la producción de proteínas recombinantes, con el fin de descubrir o mejorar la actividad y eficacia de estas cepas bacterianas contra diferentes plagas agrícolas. En este contexto, y dado que el control biológico de la $P$. xylostella aún depende de insecticidas químicos, también se considera necesario identificar nuevas estrategias, como la combinación de organismos biológicos o patógenos que contribuyan al manejo integrado de esta plaga, entendiendo también la fisiología de cada organismo.

\section{REFERENCIAS}

Benintende, G., López Meza, J., Cozzi, J. e Ibarra, J. (1999). Novel non-toxic isolates of Bacillus thuringiensis. Lett Appl Microbiol, 29, 151-155.

Bravo, A., Gill, S. y Soberón, M. (2007). Mode of action of Bacillus thuringiensis Cry and Cyt toxins and their potential for insect control. Toxicon, 49(4), 423-435.

Bravo, A., Gómez, I., Porta, H., García Gómez, B., Rodríguez Almazán, C., Pardo, L. y Soberón, M. (2012). Evolution of Bacillus thuringiensis Cry toxins insecticidal activity. Microb Biotechnol, 6(1), 17-26.
Chen, M., Chen, P., Pang, J., Lin, C., Hwang, C. y Tsen, H. (2014). The correlation of the presence and expression levels of Cry genes with the insecticidal activities against Plutella xylostella for Bacillus thuringiensis strains. Toxins, 6, 24532470.

Conte de Oliveira, A., Abreu de Siqueira, H., Vargas de Oliveira, J., da Silva, J. y Michereff, M. (2011). Resistance of Brazilian diamondback moth populations to insecticides. Sci. Agric, 68(2), 154159.

Corpoíca. (1998). Productos y procesos tecnológicos por macrorregión: contribución de Corpoíca a la investigación y al desarrollo tecnológico agropecuario. Bogotá, D. C, Colombia.

Crickmore, N., Baum, J., Bravo, A., Lereclus, D., Narva, K., Sampson, K., Schnepf, E., Sun, M. y Zeigler, D. (2016). Bacillus thuringiensis toxin nomenclature. Disponible en http://www. btnomenclature.info/.

Dai, R., Su, X., Jin, X., Zhang, J., Guan, X., Chen, C., Shu, C. y Huang, T. (2016). Cloning, expression, purification, and insecticidal activity of a novel Cry1Na3 toxin from Bacillus thuringiensis BRCZYR2. Journal of Economic Entomology, 109(3), 1064-1070.

Dosdall, L. (2014). Diamondback Moth. Disponible en http://www1.agric.gov.ab.ca/\$department/ deptdocs.nsf/all/agdex2540/\$file/622-19. pdf?OpenElement.

FAO (2005). Intercountry programme to strengthen IPM training and sustain IPM practices among vegetable farmers in South and Southeast Asia. Vegetable IPM strategy. Country reports for the bi-annual FAO Regional Vegetable IPM Programme Meeting, 25-30 April 2005, Luang Prabang, Laos PDR.

Furlong, M., Wright, D. y Dosdall, L. (2013). Diamondback moth ecology and management: problems, progress and prospects. Annual Review of Entomology, 58, 517-541. 
Gordon, R., Haynes, W., Pang, C. (1973). The genus bacillus. Us Department of Agriculture Handbook, 427. Washington DC., USDA, 109-126.

Han, G., Li, C., Liu, Q. y Xu, J. (2015). Synergistic effect of combining Plutella xylostella granulovirus and Bacillus thuringiensis at sublethal dosages on controlling of diamondback moth (Lepidoptera: Plutellidae). Journal of Economic Entomology, 108(5), 2184-2191.

Head, G. y Greenplate, J. (2012). The desing and implementation of insect resistance management programs for Bacillus thuringiensis crops. Journal GM Crops \& Food, 3(3), 144-153.

Hernández Fernández, J. (2016). Bacillus thuringiensis: a natural tool in insect pest control. En V. Gupta (ed.). The Handbook of Microbial Bioresourses. India: CABI Publishers, 121-139.

Hernández Fernández, J. y López Pazos, S.A. (2011). Bacillus thuringiensis: soil microbial insecticide, diversity and their relationship with the entomopathogenic activity. En M. Miransari (ed.), Soil microbes and environmental health. Bogotá: Nova Science Publishers, 59-80.

Hofte, H. y Whiteley, H. (1989). Insecticidal crystal proteins of Bacillus thuringiensis. Microbiological Reviews, 53(2), 242-255.

Ibiza, M. (2015). Bases de la resistencia a preparados bioinsecticidas basados en Bacillus thuringiensis en diferentes especies de insectos (tesis doctoral). Universidad de Valencia, Valencia, España.

Ibrahim. M., Griko, N., Junker, M. y Bulla, L. (2010). Bacillus thuringiensis: A genomics and proteomics perspective. Bioengineered Bugs, 1(1), 31-50.

Jiang, T., Wu, S., Yang, T., Zhu, C., Gao, C. (2015). Monitoring field populations of Plutella xylostella (Lepidoptera: Plutellidae) for resistance to eight insecticides in China. Florida Entomologist, 98(1), 65-73.

Legwaila, M., Munthaili, D., Kwerepe, B y Obopile, M. (2015). Efficacy of Bacillus thuringiensis (var. kurstaki) against diamondback moth (Plutella xylostella L.) eggs and larvae on cabbage under semi-controlled greenhouse conditions. International Journal of Insect Science, 7, 39-45.

León, G. de (2010). Caracterización del espectro de acción de la toxina CryAbMod, activa contra insectos resistentes, y su comparación con la toxina convencional Cry1Ab de Bacillus thuringiensis (tesis doctoral). Universidad Nacional Autónoma de México, México.

Lira, J., Beringer, J., Burton, S., Griffin, S., Sheets, J., Yee, S., Woosley, A., Worden, S. y Narva, K. (2013). Insecticidal activity of Bacillus thuringiensis Cry1Bh1 against Ostrinia nubialis (Hubner) (Lepidoptera: Crambidae) and other lepidopteran pest. Appl Environ Microbiol, 79(24), 7590-7597.

López Meza, J. e Ibarra, J. (1996). Characterization of a novel strain of Bacillus thuringensis. Appl Environ Microbiol, 62, 1306-1310.

López Pazos, S. (2011). Actividad biológica de proteínas Cry recombinantes de Bacillus thuringiensis sobre larvas de primer instar de Hypothenemus hampei Ferrari (Coleóptera: Scolytidae) (tesis doctoral). Universidad Nacional de Colombia, Bogotá, Colombia.

Maagd, M. de, Bravo, A. y Crickmore, N. (2001). How Bacillus thuringiensis has evolved specific toxins to colonize the insect world. Trend Genet, 17(4), 193-199.

Magalhaes, G., Vacari, A., Laurentis, V., de Bortoli, D. y Polanczyk (2014). Interactions of Bacillus thuringiensis bioinsecticides and the predatory stink bug Podisus nigrispinus to control Plutella xylostella. Journal of Applied Entomology, 1(2), 123-133.

Muñiz, R., Marín, A., Díaz, L., Gámez, A., Ávila, M., Herrera, R., Dorantes, J. y Gámez, F. (2013). Manejo integrado de la palomilla dorso de diamante Plutella xylostella (L.) en la región del bajío, México. Instituto Nacional de 
Investigaciones Forestales, Agrícolas y Pecuarias. México: Dzibal Impresos.

Nangong, Z., Wang, Q., Song, P., Hao, J., Yang, Q. y Wang, L. (2016). Synergism between Bacillus thuringiensis and Xenorhabdus nematophila against resistant and susceptible Plutella xylostella (Lepidoptera: Plutellidae). Biocontrol Science and Technology, 26(10), 1411-1419.

Nathan, S., y Kalaivani, K. (2006). Combined effects of azadirachtin and nucleopolyhedrovirus (SpltNPV) on Spodoptera litura Fabricius (Lepidoptera: Noctuidae) larvae. Biol. Control, 39, 96-104.

Navarro, D. (2010). Manejo integrado de plagas. University of Kentucky. Collegue of Agriculture, Food and Environment. Cooperative Extension Service. Disponible en http://www2.ca.uky.edu/ agcomm/pubs/id/id181/id181.pdf.

Nian, X., He, Y., Lu, L. y Zhao, R. (2014). Evaluation of the time-concentration-mortality responses of Plutella xylostella larvae to the interaction of Isaria fumosorosea with the insecticides betacypermethrin and Bacillus thuringiensis. Pest Management Science, 71(2), 216-224.

Nian, X., He, Y., Lu, L. y Zhao, R. (2015). Evaluation of alternative Plutella xylostella control by two Isaria fumosorosea conidia formulations, oil-based formulation and wettable powder combined with Bacillus thuringiensis. Pest Manag Sci, 71(12), 1675-1684.

OMS (1996). Recommended classification of pesticides by hazard and guidelines to classification 1996-1997. Organización Mundial de la Salud, IPCS, Ginebra.

Pan, Z., Xu, L., Zhu, Y., Shi, H., Chen, Z., Chen, M., Chen, Q. y Liu, B. (2014). Characterization of a new Cry2Ab gene of Bacillus thuringiensis with high insecticidal activity against Plutella xylostella. $L$. World J Microbiol Biotechnol, 30(10), 2655-2662.

Panuwet, P., Siriwong, W., Prapanontol, T., Ryan, B., Fiedler, N., Robson, M y Boyd, D. (2012).
Agricultural pesticide management in Thailand: Situation and population health risk. Environ. Sci. Policy, 17(1), 72-81.

Pigott, C. y Ellar, D. (2007). Role of receptors in Bacillus thuringiensis crystal toxin activity. Microbiology and Molecular Biology Reviews, 71(2), 255-281.

Porcar, M. y Juárez Pérez, V. (2004). Aislamiento y establecimiento de una colección de Bacillus thuringiensis. En A. Bravo y J. Cerón (eds.) Bacillus thuringiensis en el control biológico. Bogotá: Universidad Nacional de Colombia, pp. 69-100.

Reckha, B., Srinivasan, R., Kumar, A., Bharpoda, T. y Cgatterjee, H. (2011). Susceptibility of diamondback moth and cabbage head caterpillar to Bacillus thuringiensis $(B t) \delta$-endotoxins on vegetable brassicas in India. En The $6^{\text {th }}$ International Workshop on Management of the Diamondback Moth and Other Crucifer Insect Pests. Tailandia: Nakhon Pathom.

Roh, J., Choi, J., Li, M., Jin, B. y Je, Y. (2007). Bacillus thuringiensis as a specific, safe, and effective tool for insect pest control. J. Microbiol. Biotechnol, 17, 547-559.

Rosa, M., Araya, J., Guerrero, M. y Lamborot, L. (1997). Niveles de resistencia de Plutella xylostella (L.) a tres insecticidas en varias localidades de la zona central de Chile. Bol. San. Veg. Plagas, 23, 571-581.

Santos, C., Siquiera, H., Da Silva, J. y De Farias, M. (2011). Insecticide resistance in populations of the diamondback moth, Plutella xylostella (L.) (Lepidoptera: Plutellidae), from the state of Pernambuco, Brazil. Neotrop. Entomol, 40(2), 264-270.

Sarfraz, M., Dosdall, L. y Keddie, B. (2006). Diamondback moth-liost plant interactions: Implications for pest managemcnt. Crop Protection, 25, 625-639.

Sauka, D. y Benintende, G. (2008). Bacillus thuringiensis: generalidades. Un acercamiento 
a su empleo en el biocontrol de insectos lepidópteros que son plagas agrícolas. Revista Argentina de Microbiología , 40, 124-140.

Schnepf, E., Crickmore, N., Van Rie, J., Lereclus, D., Baum, J., Feitelson, J., Zeigler, D. y Dean, D. (1998). Bacillus thuringiensis and its posticidal crystal proteins. Microbiology and Molecular Biology Reviews, 62(3), 775-806.

Schünemann, N., Knaak, N. y Fiuza, L. (2014). Mode of action and specificity of Bacillus thuringiensis toxins in the control of caterpillars and stink bugs in soybean culture. ISRN microbiology, 135675. Disponible en http://doi. org/10.1155/2014/135675.

Shelton, A., Sances, F., Hawley, J., Tang, J., Boune, M., Jungers., Collins, H. y Farias, J. (2000). Assessment of insecticide resistance after the outbreak of diamondback moth (Lepidoptera: Plutellidae) in California in 1997. J. Econ. Entomol, 93(3), 931936.

Soberón, M. y Bravo, A. (2007). Las toxinas Cry de Bacillus thuringiensis: modo de acción y consecuencias de su aplicación. Biotecnología, 14, 303-314.

Srinivasan, R., Shelton, A. y Collins, H. (2011). The Sixth International Workshop on Management of the Diamondback Moth and Other Crucifer Insect Pests, 21-25 March 2011, Kasetsart University, Nakhon Pathom, Thailand. AVRDC - The World Vegetable Center, Publication No. 11-755. AVRDC The World Vegetable Center, Taiwan.

Swiecicka, I., Bideshi, D. y Federeci, B. (2008). Novel isolate of Bacillus thuringiensis subsp. thuringiensis that produces a quasicuboidal crystal of Cry1Ab21 toxic to larvae of Trichoplusia ni. Appl. Environ. Microbiol, 74(4), 923-930.

Tabashnik, B., Cushing, N. y Johnson, M. (1987). Diamondback moth (Lepidoptera: Plutellidae) resistance to insecticides in Hawaii: Intra-island variation and cross-resistance. J. Econ. Entomol, 80, 1091-1099.
Talekar, N. y Shelton, A. (1993). Biology, ecology, and management of the diamonback moth. Annu. Rev. Entomol, 38, 275-301.

Vacari, A., Otuka, A. y de Bortoli, S. (2007). Desenvolvimento de Podisus nigrispinus (Dallas, 1851) (Hemiptera: Pentatomidae) alimentado com lagartas de Diatraea saccharalis (Fabricius, 1794) (Lepidoptera: Crambidae). Arq. Inst. Biol, 74, 259-265.

Van Frankenhuyzen, K. (2009). Insecticidal activity of Bacillus thuringiensis crystal proteins. Journal of Invertebrate Pathology, 101(1), 1-16.

Wang, X., Khakame, S., Ye, C., Yang, Y. y Wu, Y. (2012). Characterization of field-evolved resistance to chlorantraniliprole in the diamond backmoth, Plutella xylostella, from China. Pest Management Science, 69(5), 661-665.

Wang, R. y Wu, Y. (2014). Dominant fitness costs of abamectin resistance in Plutella xylostella. Pest Manag Sci, 70(12), 1872-1876.

Wang, Y., Wei, R., Zhu, H. y Zhou, X. (2015). Determination of resistance to seven insecticides in Plutella xylostella L. in fields of Northern Hunan. Agricultural Science \& Technology, 15(3), 553-555.

Xia, Y., Lu, Y., Shen, J., Gao, X., Qiu, H. y Li, J. (2014). Resistance monitoring for eight insecticides in Plutella xylostella in central China. Crop Protection, 63, 131-137.

Zalucki, M., Shabbir, A., Silva, R., Adamson, D., ShuSheng, L. y Furlong, J. (2012). Estimating the economic cost of one of the world's major insect pests, Plutella xylostella (Lepidoptera: Plutellidae): Just how long is a piece of string? Journal of Economic Entomology, 105(4), 1115-1129. 